\title{
Long term complications of Polycystic ovary syndrome
}

\author{
Garima Kachhawa* and Anju Singh \\ Department of Obstetrics and Gynaecology, All India Institute of Medical Sciences, India
}

Submission: July 15, 2017; Published: July 28, 2017

*Corresponding author: GarimaKachhawa, Anju Singh, Department of Obstetrics and Gynaecology, All India Institute Of Medical Sciences, Delhi, India, Email: garimakhadgawat@gmail.com

\begin{abstract}
Polycystic ovary syndrome (PCOS) is emerging as most common endocrine disorder during reproductive years with wide spectrum of clinical manifestations during the life span of affected female. During reproductive years, ovulatory dysfunction in these women leads to increased risk of infertility and adverse obstetric outcomes. As the age advances, apart from adverse reproductive out comes which is a cause of immediate concern, there is increased risk for development of type-2 diabetes mellitus, metabolic syndrome, hypertension, cardiovascular morbidity and mortality, risk of endometrial cancer, impaired immune function and psychiatric illness. Considering the increasing incidence, the need of early diagnosis and long term follow up to address serious health implications, specialised "PCOS CLINIC" should be established with experts from various disciplines.
\end{abstract}

Keywords: PCOS; IR; CVD

List of Abbreviations: PCOS: Polycystic Ovary Syndrome; IR: Insulin Resistance; BMI: Body Mass Index; DM: Diabetes Mellitus; CVD: Cardiovascular Disease; ESHRE: European Society of Human Reproduction and Embryology; NCEP: National Cholesterol Education Program

\section{Introduction}

Polycystic ovary syndrome (PCOS) is emerging as most common endocrine disorder in women during reproductive years with a prevalence ranging from 6 to 10\%. 1,2 Clinically, it presents with ovulatory dysfunction, hyper androgenism and/or polycystic ovarian morphology with exclusion of other etiologies $[1,2]$. It is a heterogenous condition with multiple clinical phenol types widely depending on age, genotype, ethnicity, bodyweight, lifestyle and environmental factors differently affecting the early and long-term risks.

\section{Metabolic Risk}

In PCOS, the underlying hormonal imbalance characterised by insulin resistance and increased androgen production pre dispose to the risk of metabolic abnormalities. Metabolic Syndrome comprises of insulin resistance (IR), dyslipidemia, and obesity as key features. It is identified clinically as waist circumference $>88 \mathrm{~cm}$, impaired glucose tolerance, blood pressure $>130 / 85 \mathrm{mmHg}$, triglycerides $>150 \mathrm{mg} / \mathrm{dl}$ and highdensity lipoprotein $<50 \mathrm{mg} / \mathrm{dl}$. 3Around $40-50 \%$ of women with PCOS also have these features, so it may be considered as 'ovarian expression of metabolic syndrome' [3]. Despite considerable overlap between PCOS and metabolic syndrome; it is important to note that both are not identical or interchangeable.

The complex pathophysiology is affected by number of factors and obesity is most important of all. The prevalence of obesity in PCOS is $42-74 \%$ which is much higher as compared to general population $(25 \%)$. There is bidirectional relationship of obesity with PCOS, as excessive weight gain increases PCOS prevalence and women with PCOS are more inclined to weight gain. The superimposed obesity is also associated with more profound hyper insulinemia and hyperactivity of hypothalamicpituitary-adrenal axis leading to increased adrenal androgens and worsening of hyper androgenic state. It exacerbate severe reproductive phenotypes characterised by hyper androgenism with chronic an ovulation. More so ever, it also has a synergistic effect on development of cardio-metabolic risk, diabetes and endometrial cancer among PCOS women.

IR is second component of metabolic syndrome in which endogenous or exogenously administered insulin has less than normal biological effects on tissues (fat, muscle and liver). Although IR is not a diagnostic criterion of PCOS but is seen 
in $50-80 \%$ of PCOS women independent of BMI making them more susceptible to pre-diabetes and accelerated progression to diabetes [4]. The International Diabetes Federation has also identified PCOS as a significant non-modifiable risk factor associated with Type II DM [5]. Hence the ESHRE/ASRM sponsored PCOS Consensus Workshop Group recommend an oral glucose tolerance test (OGTT) in all overweight women with PCOS [6]. It should also be kept in mind that impaired glucose tolerance may not be present at time of diagnosis of PCOS and this risk increases with time, there by warranting long term follow up in these patients. Apart from increasing the risk of DM, IR also has a pivotal role in development of dyslipidemia mediated in part by stimulation of lipolysis and altered expression of lipoprotein lipase and hepatic lipase. It is characterised by increased total triglycerides, low density lipoproteins (LDL-C) and decreased high density lipoprotein (HDL-C) cholesterol. Dyslipidemia is reported in upto $70 \%$ of PCOS women according to NCEP guidelines Hypertension, which is also a component of metabolic syndrome is found more in PCOS patients, atleast later in life if not present during reproductive years at time of presentation. Prevalence varies from $3.3-22 \%$ in third and fourth decade of life which further increases to $28.1-39 \%$ for menaupausal women.

\section{Cardiovascular Risk}

As already discussed, PCOS women exhibit an increased prevalence of classic risk factors for cardiovascular disease (CVD) such as obesity, dyslipidemia, impaired glucose tolerance and diabetes. Hyper insulinemia contributes to the prothrombotic state by reducing fibrinolysis and raising levels of plasminogen activator inhibitor-1. Apart from these, Non classic CVD risk factors related to systemic inflammatory state \& impaired fibrinolysis such as increased C-reactive protein (CRP), homocysteine, tumor necrosis factor- $\alpha$, IL-6, IL-18 etc. are found in excess in women with PCOS [7]. Anatomical evidence of increased subclinical markers of atherosclerosis (endothelial dysfunction, impaired pulse wave velocity, increased carotid intima media wall thickness, presence of carotid plaque and increased coronary artery calcification) are also more common in PCOS than in controls, even after adjustments for age and BMI [8]. Obstructive sleep apnea (OSA) is a known independent cardiovascular risk factor and has been found to be 5-30 times more common in women with PCOS as compared to controls. So the higher prevalence of all these markers result in increased CVD risk among PCOS women with relative risk of 2.02 for coronary heart disease and 1.55 after adjusting for BMI [9]. Risk for thrombosis and stroke is also increased two times [10]. Since all of cardiovascular risk factors may not be present at time of diagnosis of PCOS, there is need of long term follow up for early identification.

\section{Oncology Risk}

Women with PCOS have chronic anovulatory cycles resulting in an unopposed estrogen action on endometrium. It leads to endometrial hyperplasia which may progress to endometrial cancer. This predisposition is further increased by the presence of obesity, Type II DM, subclinical inflammation and metabolic syndrome, which are known risk factors for endometrial cancer and are highly represented in PCOS populations. Therefore, women with PCOS of all ages are at 3-4 times increased risk of endometrial hyperplasia and cancer [11]. Considering this risk, ESHRE/ASRM Consensus Group has recommended a proper endometrial surveillance with ultrasound and/or biopsy to assess endometrial thickening in PCOS women who experience extended period of amenorrhea. To minimise this risk, in these women periodic progesterone withdrawal is also recommended, at least four episodes per year [12]. Regular with drawl bleeding with monthly progesterone or oral contraceptive pills ensure cyclicity in menstruation and prevent endometrial build up ultimately reducing the risk of endometrial cancer.

There is limited and contradictory evidence regarding the risk of ovarian and breast cancerin women with PCOS; so currently, the ESHRE/ASRM consensus statement does not recommend routine surveillance strategy and/or clinical care to detect ovarian and breast cancer in women with PCO [12]. There is also insufficient evidence to evaluate any association of PCOS with vaginal, vulvar, and cervical cancer.

\section{Psychological Problems}

PCOS compromises body image due to obesity, acne and excess hair. Infertility and long term health related concerns also result in reduced quality of life and adverse impact on mood and psychological well-being. So, women with PCOS are more prone to depression, anxiety, low self-esteem, negative body image, and psychosexual dysfunction $[13,14]$. Increased rate of depressive symptoms compared to non-BMI matched controls with prevalence ranging from 28 to $64 \%$ (for depression) and 34 $57 \%$ (for anxiety) have been reported in women with PCOS13. Therefore, all psychosocial issues are need to be explored and addressed as part of PCOS assessment and management.

\section{Management}

Apart from detailed history and examination, initial assessment of all PCOS patients should also aim to determine risk factors for long term complications. Investigations at first visit should include:

\section{o Measurement of BMI and waist circumference}

o Blood pressure should be routinely checked at each visit

o $\quad 2 \mathrm{hr} 75 \mathrm{~g}$ oral glucose tolerance test ( $2 \mathrm{hr}$ value should be $<140 \mathrm{mg} / \mathrm{dl}$ ), repeat every 2 yrs

o Fasting lipid profile (Total cholesterol, triglycerides, low density lipoprotein, high density lipoprotein)

o Transvaginal ultrasound for endometrial thickness and/or endometrial biopsy if present with abnormal uterine bleeding 


\section{Global Journal of Reproductive Medicine}

\section{o Pscychological assessment}

Lifestyle changes, including hypo-caloric diet and physical exercises, are recommended as first-line approach for all PCOS women. Pharmacotherapy is targeted to symptoms and should not be used as an alternative to lifestyle modifications. It includes insulin sensitising agents like metformin; Inositol isomers, particularly myoinositol (MI) and D-chiro-inositol(DCI), statins, anti-obesity agents like orlistat with each of the agent having its own advantage and disadvantages. Bariatric surgery may be an option for morbidly obese women with PCOS (BMI $>40 \mathrm{~kg} / \mathrm{m}^{2}$ OR BMI $>35 \mathrm{~kg} / \mathrm{m}^{2}$ with a high-risk obesity related condition), if standard weight loss strategies have failed [15].

\section{Conclusion}

Overall, women with PCOS show an increased risk of obstetric, cardiovascular, metabolic, and psychological complications compared to non-PCOS women. In the light of these considerations, all women with a diagnosis of PCOS should be screened for all risk factors with aim to select specific treatment, lifestyle modifications, customizing the therapy and long term follow-up.

\section{References}

1. Azziz R, Woods KS, Reyna R, Key TJ, Knochenhauer ES, et al. (2004) The prevalence and features of the polycystic ovary syndrome in an unselected population. J Clin Endocrinol Metab 89(6): 2745-2749.

2. Asuncion M, Calvo RM, Millan SJL, Sancho J, Avila S, et al. (2000) A prospective study of the prevalence of the polycystic ovary syndrome in unselected Caucasian women from Spain. J Clin Endocrinol Metab 85(7): 2434-2438.

3. Rotterdam ESHRE/ASRM-Sponsored PCOS Consensus Workshop Group. Revised 2003 consensus on diagnostic criteria and long-term health risks related to polycystic ovary syndrome (PCOS). Hum Reprod 2004:19(1): 41-47.

4. Legro RS, Castracane VD, Kauffman RP (2004) Detecting insulin resistance in polycystic ovary syndrome: purposes and pitfalls. Obstet Gynecol Surv 59(2): 141-154.
5. Alberti KG, Zimmet P, Shaw J (2007) International Diabetes Federation a consensus on Type 2 Diabetes prevention. Diabet Med 24(5): 451463.

6. Salley KE, Wickham EP, Cheang KI, Essah PA, Karjane NW, et al. (2007) Glucose intolerance in polycystic ovary syndrome - a position statement of the Society Androgen Excess. J ClinEndocrinolMetab 92: 4546-4556.

7. Meyer C, McGrath BP, Teede HJ (2005) Overweight women with polycystic ovary syndrome have evidence of subclinical cardiovascular disease. J Clin Endocrinol Metab 90(10): 5711-5716.

8. Meyer C, McGrath BP, Cameron J, Kotsopoulos D, Teede HJ (2005) Vascular dysfunction and metabolic parameters in polycystic ovary syndrome.J ClinEndocrinolMetab 90(8): 4630-4635.

9. de Groot PC, Dekkers OM, Romijn JA, Dieben SW, Helmerhorst FM (2011) PCOS, coronary heart disease, stroke and the influence of obesity: a systematic review and meta-analysis. Human Reproduction update 17(4): 495-500.

10. Glintborg D, Hass RK, Nybo M, Abrahamsen B, Anderson M (2015) Morbidity and medicine prescription in a nationwide Danish population of patients diagnosed with polycystic ovary syndrome. European Journal of Endocrinology 172(5): 627-638.

11. Barry JA, Azizia MM, Hardiman PJ (2014) Risk of endometrial, ovarian and breast cancer in women with polycystic ovary syndrome: a systematic review and meta-analysis. Hum Reprod Update 20(5): 748758.

12. Fauser BC, Tarlatzis BC, Rebar RW, et al. (2012) Consensus on women's health aspects of polycystic ovary syndrome (PCOS): the Amsterdam ESHRE/ASRM-Sponsored 3rd PCOS Consensus Workshop Group. FertilSteril 97(1): 28-38.

13. Coffey S, Mason H (2003) The effect of polycystic ovary syndrome on health related quality of life. Gynecol Endocrinol 17(5): 379-386.

14. Deeks A, Gibson-Helm M, Teede H (2010) Anxiety and depression in polycystic ovary syndrome (PCOS): a comprehensive investigation. FertilSteril 93(7): 2421-2423.

15. National Institute for Health and Clinical Excellence. Obesity:Guidance on the prevention, identification, assessment and management of overweight and obesity in adults and children. NICE clinical guideline 43. Manchester; NICE: 2006.
Your next submission with Juniper Publishers will reach you the below assets

- Quality Editorial service

- Swift Peer Review

- Reprints availability

- E-prints Service

- Manuscript Podcast for convenient understanding

- Global attainment for your research

- Manuscript accessibility in different formats ( Pdf, E-pub, Full Text, Audio)

- Unceasing customer service

Track the below URL for one-step submission https://juniperpublishers.com/online-submission.php 